Thorax (1972), 27, 185.

\title{
Pulmonary function in tropical eosinophilia
}

\author{
M. S. NES A R A J A H \\ Department of Physiology, Faculty of Medicine, University of Ceylon, Colombo 8
}

\begin{abstract}
Pulmonary function studies were carried out on 23 patients with tropical eosinophilia. These showed an obstructive ventilatory defect in patients with symptoms for less than one month, and a restrictive ventilatory defect in addition to obstruction in those with symptoms for one to four months. These findings are correlated with the pathological changes observed by other workers in patients suffering from tropical eosinophilia.
\end{abstract}

Tropical eosinophilia is characterized by a dry, irritating, and intermittent diurnal cough that later becomes mainly nocturnal, dyspnoea on exertion and later even at rest, wheezing, and a high eosinophil count in the peripheral blood. The clinical features (Islam, 1964), pathology (Udwadia and Joshi, 1964; Danaraj, Pacheco, Shanmugaratnam, and Beaver, 1966), and radiological appearances of the chest (Herlinger, 1963; Khoo and Danaraj, 1960) have been well described. There is now considerable evidence for the filarial aetiology of the disease (Joshi, Udwadia, and Gadgil, 1969), and the efficacy of the antifilarial drug diethyl carbamazine in its treatment (Danaraj, 1958; Narang and Jain, 1966) is also well established. Pulmonary function studies in this condition, however, have received less attention.

The present study was undertaken to assess respiratory function in a group of patients with tropical eosinophilia in Ceylon and to correlate these findings with the pathological changes in the lungs.

\section{MATERIALS AND METHODS}

Only patients who fulfilled the criteria recommended by Donohugh (1963) for the diagnosis of tropical eosinophilia were selected. The criteria are as follows: a history of a dry, irritating cough worse at nights and accompanied by attacks of wheezing dyspnoea; eosinophil counts in the peripheral blood of over $2,000 / \mathrm{mm}^{3}$; a positive filaria complement fixation test (FCFT); and a clinical and haematological response to diethylcarbamazine. All patients giving a past history of chronic bronchitis, bronchial asthma, pneumonia, pleurisy or pulmonary tuberculosis were excluded. Patients who had previously had any form of treatment for tropical eosinophilia were also excluded.
Of the 23 patients studied, 18 were males and 5 females. Their ages ranged from 13 to 63 years with a mean of 34.6 years. The duration of symptoms was less than one month in nine patients and from one to four months in the remaining 14 . The patients were accordingly divided into two groups-group A, those with symptoms of less than one month's duration, and group B, those with symptoms of more than one month's duration.

The following pulmonary function tests were carried out. The total lung capacity (TLC), functional residual capacity (FRC), and residual volume (RV) were measured by the closed-circuit helium dilution method (Gilson and Hugh-Jones, 1949) using a Godart Pulmonet. The vital capacity (VC), forced vital capacity (FVC), and forced expired volume in one second (FEV 1.0) were measured with a low-resistance Aika spirometer and the peak expiratory flow rate (PEFR) with a Wright peak flow meter. The lung volumes were corrected to volumes at BTPS.

For purposes of comparison, these lung function tests were also carried out on a group of 31 healthy Ceylonese adults of comparable mean age and sex.

\section{RESULTS}

The normal values for lung volumes and expiratory flow rates are dependent on age, sex, height, and weight. As insufficient data are available for normal Ceylonese subjects, all results obtained for patients and for normal subjects were expressed as percentages of predicted values for persons of European descent. The prediction formulae used were those recommended by Cotes (1968).

The mean values and the standard deviations for the lung volumes and expiratory flow rates of the normal subjects and patients are shown in Table I. The VC, FEV 1.0, FEV $_{1.0} \%$, and PEFR were found to be significantly lower in the 
T A B L E I

MEAN VALUES (AND STANDARD DEVIATIONS) FOR LUNG VOLUMES AND EXPIRATORY FLOW RATES FOR NORMAL SUBJECTS AND PATIENTS

\begin{tabular}{|c|c|c|c|c|c|c|}
\hline & $\mathrm{VC}$ & RV & TLC & $\mathrm{FEV}_{1 \cdot 0}$ & $\mathrm{FEV}_{\%}$ & PEFR \\
\hline $\begin{array}{l}\text { Normal subjects } \\
\qquad(n=31)\end{array}$ & $\begin{array}{l}77 \cdot 2 \\
(8 \cdot 7)\end{array}$ & $\begin{array}{l}64 \cdot 2 \\
(12 \cdot 9)\end{array}$ & $\begin{array}{l}72 \cdot 3 \\
(7 \cdot 0)\end{array}$ & $\begin{array}{l}78 \cdot 5 \\
(8 \cdot 5)\end{array}$ & $\begin{array}{c}106 \cdot 1 \\
(5 \cdot 3)\end{array}$ & $\begin{array}{c}91.0 \\
(11 \\
(1.0)\end{array}$ \\
\hline \multirow[t]{2}{*}{$\begin{array}{l}\text { All patients } \\
\quad(\mathrm{n}=23)\end{array}$} & $\begin{array}{c}56 \cdot 3 \\
(16 \cdot 6)\end{array}$ & $\begin{array}{r}85 \cdot 6 \\
(19 \cdot 5)\end{array}$ & $\begin{array}{c}65 \cdot 3 \\
(14 \cdot 7)\end{array}$ & $\begin{array}{c}47 \cdot 2 \\
(16 \cdot 8)\end{array}$ & $\begin{array}{l}89 \cdot 6 \\
(9 \cdot 6)\end{array}$ & $\begin{array}{c}52.8 \\
(19.7)\end{array}$ \\
\hline & $\begin{array}{c}P< \\
0.001\end{array}$ & $\begin{array}{c}P< \\
0.001\end{array}$ & $\begin{array}{l}\mathrm{P}> \\
0.02\end{array}$ & $\begin{array}{c}\mathbf{P}< \\
0.001\end{array}$ & $\begin{array}{c}P< \\
0.001\end{array}$ & $\begin{array}{c}P< \\
0.001\end{array}$ \\
\hline
\end{tabular}

The individual values from which the mean and standard deviations have been calculated have been expressed as percentages of the predicted values (see text).

patients than in the normal subjects $(P<0001)$. The RV, on the other hand, was significantly higher $(\mathbf{P}<0.001)$ whereas the TLC was not significantly different from that of healthy subjects $(P>0.02)$.

The results obtained for the two groups of patients, A and B, are summarized in Table II. Although the mean values for the lung volumes and flow rates were lower for group $B$ than for group $A$, the differences were significant only for the expiratory flow rates.

\section{T A B L E I I}

MEAN VALUES (AND STANDARD DEVIATIONS) FOR LUNG VOLUMES AND EXPIRATORY FLOW RATES FOR PATIENTS WITH SYMPTOMS OF < 1 MONTH'S DURATION (GROUP A) AND $>1$ MONTH'S DURATION (GROUP B)

\begin{tabular}{|c|c|c|c|c|c|c|}
\hline Group & VC & RV & TLC & FEV $_{1 \cdot 0}$ & $\underset{\%}{\mathrm{FEV}_{1 \cdot 0}}$ & PEFR \\
\hline A & $\begin{array}{c}63.9 \\
(17 \cdot 6)\end{array}$ & $\begin{array}{c}87 \cdot 1 \\
(20 \cdot 8)\end{array}$ & $\begin{array}{c}68 \cdot 3 \\
(16 \cdot 3)\end{array}$ & $\begin{array}{c}59.0 \\
(14.4)\end{array}$ & $\begin{array}{l}97 \cdot 5 \\
(4 \cdot 8)\end{array}$ & $\begin{array}{l}66 \cdot 8 \\
(9 \cdot 8)\end{array}$ \\
\hline \multirow[t]{2}{*}{ B } & $\begin{array}{c}51 \cdot 4 \\
(14 \cdot 5)\end{array}$ & $\begin{array}{c}84 \cdot 2 \\
(19 \cdot 3)\end{array}$ & $\begin{array}{c}62 \cdot 6 \\
(13 \cdot 3)\end{array}$ & $\begin{array}{c}39 \cdot 6 \\
(13 \cdot 7)\end{array}$ & $\begin{array}{l}84 \cdot 5 \\
(8 \cdot 5)\end{array}$ & $\begin{array}{c}43 \cdot 8 \\
(19 \cdot 5)\end{array}$ \\
\hline & NS & NS & NS & $\begin{array}{l}\mathrm{P}< \\
0.01\end{array}$ & $\begin{array}{c}P< \\
0.001\end{array}$ & $\begin{array}{l}\mathrm{P}< \\
0.01\end{array}$ \\
\hline
\end{tabular}

The individual values for which the mean values and standard deviations have been calculated have been expressed as percentages of predicted values (see text).

The TLC for group B patients was found to be significantly lower than that of normal subjects $(P<0.01)$ whereas for group A patients the difference was not significant $(P>0 \cdot 2)$.

\section{DISCUSSION}

In the present study, the selection of cases was based on the fulfilment of rather rigid criteria and so it is possible that patients with milder or atypical forms of the disease may have been excluded (Donohugh, 1963); further, all patients studied had a history of less than four months' duration.
The lung function studies suggest that the main defect is a mild to moderate airways obstruction which is present from the very outset of the disease and deteriorates if untreated. The increase in residual volume and decrease in vital capacity are probably due to the premature closure of narrowed airways.

The TLC in group A patients is not signifi $=$ cantly different from that in normal subjects. suggesting that the parenchymal changes in the lung, if any, are only minimal in the early stagesx of the disease. The TLC in the group B patients who have had the disease for more than oneiv month is, however, significantly lower $(P<0.01)$ bo than in normal subjects, suggesting that there is damage to the lung parenchyma as the disease progresses. It is evident that, in these patients $\overrightarrow{\vec{C}}$ both airways obstruction and lung parenchymalo damage are responsible for the disability.

Udwadia (1967) observed a restrictive pattern of lung function in all his patients and only about one-fifth of the patients showed obstruction to ${ }^{N}$ the airways. More than $90 \%$ of the patients in his series, however, had symptoms for more than three months and ranging up to 11 years. The⿳亠二口 predominantly restrictive pattern would thuso seem to be characteristic of the later stage of the $\stackrel{\mathbb{Q}}{\stackrel{\mathbb{Q}}{ }}$ disease. Azad Khan, Patra, Banu, and Rabbee $\vec{\Rightarrow}$ (1970) have also observed a greatly reduced VC응 with a normal $\mathrm{FEV}_{1 \cdot 0}$ in all their patients and con-? clude that there is no obstructive ventilatoryọ defect and that the pulmonary lesion is a restrictive one. The duration of symptoms is not repor-으 ted and it is possible that their patients, too, may have had the disease for some considerable length of time.

Lung biopsy studies by Udwadia and Joshio (1964) and Danaraj et al. (1966) have shown that the pathological changes in the lung depend ono the duration of the disease. According to these authors, the earliest lesions observed (in patientso who have had the disease for up to two weeks only) are patchy and consist of an outpouring of histiocytes into the alveolar, interstitial, peri- $N$ bronchial, and perivascular spaces. The paren-N chymal lung damage observed, according to these 0 authors, was minimal. This pathology is consis-o tent with the normal TLC observed in group $A \underset{\Phi}{\complement}$ patients.

The troublesome symptom of dyspnoea with 0 wheezing in these patients is related to the airway obstruction, as shown by the low peak expiratory $\mathbb{D}$ flow rate, $\mathrm{FEV}_{1 \cdot 0}$, and $\mathrm{FEV}_{1 \cdot 0} \%$. The significantly $\mathbb{\mathbb { D }}$ higher RV and lower VC with normal TLC in these patients can also be explained on the basis of bronchial obstruction. 
The pulmonary lesions occurring in patients with symptoms of one to three months' duration have been described by Udwadia and Joshi (1964) and by Danaraj et al. (1966) as an acute eosinophilic infiltration with the formation of eosinophilic abscesses and an eosinophilic bronchopneumonia. These lesions are mainly peribronchial and perivascular and the alveolar walls are found to be disintegrated with a distorted lung architecture. Bronchioles show infiltration with eosinophils, oedema of the wall with a disrupted musculature and blocking of the lumen with the shed mucous membrane and clumps of eosinophils. These workers also observed that fibrosis was not uncommonly associated with these acute lesions described above. The progressive pathological changes in the lung observed one to three months after the onset of the illness fit the pattern of lung function seen among group B patients in the present series, namely a significant decrease in TLC with a degree of obstruction to the airways worse than in patients who have had the disease for a shorter time.

In patients whose disease is of long standing (two years and over) a characteristic feature besides histiocytic infiltration is the marked fibrosis (Udwadia and Joshi, 1964). This would no doubt lead to the predominantly restrictive type of lung lesion which has been described by both Udwadia (1967) and Azad Khan et al. (1970). None of the patients studied in the present series suffered from the disease for more than four months.

This research was supported by a grant from the Wellcome Trust, U.K.

I wish to thank the visiting physicians of the General Hospital, Colombo, for permission to carry out the lung function tests on their patients, Miss
Vallimani Kanapathipillai for her help with the lung function tests, and Dr. M. M. Ismail for carrying out the filaria complement fixation tests.

\section{REFERENCES}

Azad Khan, A. K., Patra, R. W. T., Banu, S. A., and Rabbee, M. F. (1970). Spirometry in tropical pulmonary eosinophilia. Brit. J. Dis. Chest, 64, 107.

Cotes, J. E. (1968). Lung Function. Assessment and Application in Medicine, 2nd ed. Blackwell Scientific Publications, Oxford.

Danaraj, T. J. (1958). The treatment of eosinophilic lung (tropical eosinophilia) with diethylcarbamazine. Quart.J. Med., n.s., 27, 243.

-, Pacheco, G., Shanmugaratnam, K., and Beaver, P. C. (1966). The etiology and pathology of eosinophilic lung (tropical eosinophilia). Amer. J. trop. Med. Hyg., 15, 183.

Donohugh, D. L. (1963). Tropical eosinophilia. New Engl. J. Med., 269, 1357.

Gilson, J. C., and Hugh-Jones, P. (1949). The measurement of the total lung volume and breathing capacity. Clin. Sci., 7, 185.

Herlinger, H. (1963). Pulmonary changes in tropical eosinophilia. Brit. J. Radiol., 36, 889.

Islam, N. (1964). Tropical Eosinophilia. Anwara Islam, Chittagong.

Joshi, V. V., Udwadia, F. E., and Gadgil, R. K. (1969). Etiology of tropical eosinophilia. A study of lung biopsies and review of published reports. Amer. J. trop. Med. Hyg., 18, 231.

Khoo, F. Y., and Danaraj, T. J. (1960). The roentgenographic appearance of eosinophilic lung (tropical eosinophilia). Amer. J. Roentgenol., 83, 251.

Narang, R. K., and Jain, S. C. (1966). Oral diethylcarbamazine in tropical pulmonary eosinophilia. Brit. J. Dis. Chest, 60, 93.

Udwadia, F. E. (1967). Tropical eosinophilia-a correlation of clinical, histopathologic and lung function studies. Dis. Chest, 52, 531.

—, and Joshi, V. V. (1964). A study of tropical eosinophilia. Thorax, 19, 548. 